\title{
Farming Not Alone: Farmville Play and the Implications on Social Capital
}

\author{
Shaojung Sharon Wang \\ Institute of Marketing Communication, National Sun Yat-sen University, Taiwan \\ Email: shaowang@faculty.nsysu.edu.tw \\ Received 18 August 2014; revised 21 September 2014; accepted 17 October 2014 \\ Copyright (C) 2014 by author and Scientific Research Publishing Inc. \\ This work is licensed under the Creative Commons Attribution International License (CC BY). \\ http://creativecommons.org/licenses/by/4.0/ \\ (c) (i) Open Access
}

\begin{abstract}
This study explored the relationship between Farmville play and social capital. The implications of social game play for players' psychological wellness were also assessed. Using survey data collected from Farmville players in Taiwan, it was found that the intensity of Farmville play was positively associated with players' perceived bridging and bonding social capital. The extent to which intensive Farmville play may lead to the psychological benefits of enhanced life satisfaction and reduced loneliness was discussed. In addition, players who tended to add unacquaintances were more likely to perform better than those who added people they knew. However, connecting with existing contacts through the game provides higher sense of bonding social capital. Implications on the concept of weak and strong ties were also discussed.
\end{abstract}

\section{Keywords}

Farmville, Facebook, Social Capital, Life Satisfaction, Loneliness

\section{Introduction}

The development of new information communication technology (ICT) brings people together and creates a sense of belonging in the virtual community [1]. Online games, such as massive multiplayer online role playing games (MMORPGs), allow hundreds and even thousands of people to play and interact simultaneously. The players of these games can maintain a regular character that grows and changes to compete with other characters. They are given opportunities to interact with other players and participate in a socialized virtual environment [2] [3]. Online game communities are thus structured similar to the "third place", which facilitates sociability among players in the virtual world [4] and promotes offline social connections by stimulating collective activities [5]. Researchers have further identified the function of social support [6], social capital [7], and the socioemotional aspects [8] of online games. 
Since third-party developer tools were released by Facebook in 2007, a new class of games called social games has been designed and becomes a phenomenon. This term refers to games that have minimal barriers to entry and are specifically embedded within social networking sites (SNSs) that use the players' social networks for enhancing gaming experiences [9]. There are four major components of social games: SNS based, multiplayer, real identity, and casual gaming [10]. Popular social games such as Farmville and Pet Society are based on customization and resource management [9] which bring people together to share in the responsibility for social interaction without actual copresence or interaction. The motivation to play social games lies in the psychological need to be in the company of others [11] and use the game to stimulate future social interactions [9].

However, while social capital has been linked to positive social outcomes, the psychological benefits reaped from Facebook use are mixed [12] [13]. In addition, although recent research has found that the relatively heterogeneous nature of MMORPG communities serve as potential sources of bridging social capital [7] and can even contribute to bonding social capital due to the collaborative nature of the games [14], mixed effects of MMORPG play were also produced. While researchers have investigated the sociality of virtual worlds in the MMORPG settings, not much has been done on social games as they are relatively newer. The goal of this study is to explore the intensity of Farmville play and its implications on social capital and psychological wellness.

\section{Literature Review}

The notion of social capital broadly suggests that the resources inherent in one's relationships may be used to achieve economic ends [15]. Social capital is further defined as the relationships between social actors and organizations that can facilitate action and create value [16]. It is an "investment in social relations by individuals through which they gain access to embedded resources to enhance expected returns of instrumental or expressive actions" [17].

Farmville players gain top performers by having as many neighbors as possible. For example, visiting a neighbor's farm allows players to complete tasks, such as fertilizing a few of their crops, feeding their animals, and scaring away crows and gophers, to earn cash and game experience. However, players can visit a given neighbor only once a day, meaning the more neighbors one has, the more one can visit to earn daily cash and game experience. Having many neighbors also increases the chance someone will return the favor. In addition, players in co-op farming challenges with friends build stables, add facilities, decorate, and expand their property to level up. The morein-game neighbors one has, the faster one can complete the task to advance. In fact, it is almost impossible to exp and land ownership, complete challenges, and even advance in this game without a certain number of in-game neighbors unless players spend real money.

However, the extent to which players spend real money on virtual items may be moderate according to a recent study on players' engagement with various features of social game play [18]. The rationale is that to avoid spending too much money, players must aggregate and mobilize their social networks to advance in the game. Farmville players invite friends as in-game neighbors to receive more in-game benefits and achieve higher scores within a larger friend network. Players are generally open to the gaming community to exchange for information, and many online groups or discussion boards are designed for players to obtain many friends as in-game neighbors [18]. Therefore,

H1: The more in-game neighbors the players have, the higher the game level they achieve.

Social capital is a collection of resources within the structure of relationships. A social network is one of the elements individuals can use to augment social capital and thus gain benefits via information transforming and value sharing. SNSs like Facebook allow users to maintain existing relationships and forge new contacts through information sharing and communication features [12]. Social games are not only grounded in players' existing social networks enabling players to interact with acquaintances but also allow players to meet formerly unknown others as these games are embedded in the SNS platform. In the Farmville setting, to achieve more in the game, players interact with other players who are existing contacts or enlarge their social networks by adding new people as in-game neighbors. One's social networks encompass people who are closely linked and loosely connected, all with more or less different potential to support one another [19]. Thus,

H2: Using the game to connect with existing contacts is positively associated with the game level players achieve.

H3: Using the game to link to new people is positively associated with the game level players achieve.

Social capital is about the value of social networks that can bridge diverse individuals and bond similar 
in-group members with norms of reciprocity. According to Putnam [20], bridging social capital is "outward looking and encompass people across diverse social cleavages" and is "better for linkage to external assets and for information diffusion” (p. 22). Bridging social capital connects different individuals, groups, or communities and often refers to wider outreach involving many people. Bridging social capital is often linked to "weak ties" that explain the loose connections among individuals without necessarily having emotional support. Although building connections with heterogeneous groups is likely to be fragile, it is also more likely to foster social inclusion. SNSs, in particular, provide a means for individuals to easily create and maintain broader and diffused networks of relationships with minimal cost, allowing weak ties to develop and strengthen.

Bonding, on the other hand, "tends to reinforce exclusive identities and homogeneous groups" and can provide "social and psychological support" for members of a group [20]. Bonding social capital emphasizes the social cohesion within the group structure, which engenders a sense of belonging that usually applies to a limited number of individuals. Bonding social capital explains the connections between people with similar objectives, particularly those manifested in strongly tied individuals, such as family members and close friends who support each other emotionally or substantively [21].

Recent research [12] has adopted measures differentiating between bridging and bonding social capital [21] to examine the use of Facebook to increase users' two dimensions of social capital. Facebook use is found to be a low-cost way of maintaining large loosely tied social networks, confirming the bridging benefits of the site; however, the extent to which Facebook use contributes to bonding social capital is not clear [22]. In fact, only direct communication between pairs on Facebook is associated with greater feelings of bonding social capital, whereas bridging social capital is mainly related to users' overall friend network size [23]. The findings of these studies suggest that it is not the general consumption of the site that fosters the sense of bonding; rather, how a user engages in specific behaviors and connects with specific types of people through the site provides contextual interaction between strong ties.

MMORPG is considered a virtual world that provides levels of social presence; in that world, social interaction and engagement are also fostered [7]. Although MMORPG players reported greater interference in real-life socialization, they also experienced greater enjoyment and made new friends [24]. Communication with other players is an enjoyable activity during game play. Social games like Farmville are different from MMORPGs because players need to be "friends" on Facebook to play games with one another. In other words, being Facebook friends is a prerequisite of social game play, and players may even become friends with formally unknown others through online discussion forums, game-related groups, or mutual friends. Players are encouraged to augment online social networks from which they are able to draw potential resources [12] while some even join the game because they receive invitations from existing friends [12]. The feature of the game embedded in the settings of Facebook also allows players to keep track of each other's progress through their wall postings or game-related notices via the site's interface. The casual nature of weak tie-based social interaction and information exchange may also drive acquisition and engagement to an extent. Bridging social capital might be augmented by this type of game that supports loose social ties for building links to external resources. Players who are actively engaged and enthusiastically involved in the game are more likely to create and maintain loose relationships through the weak tie based social interaction and perceive a sense of oneself as part of the larger community. Thus,

H4: There is a positive relationship between the intensity of Farmville play and players' perceived bridging social capital.

Many online gamers play with their real-life family and friends [21], which is another indication that socialization is a significant component in many online game environments. Sociability creates a culture in which people feel comfortable to communicate and interact with each other in the virtual community, enabling the development of "affective ties" among online group members. Farmville, embedded in the Facebook platform, is also played within players' social networks and often built more around close relationships. Some players play as a means of seeking social interaction with existing members of their friends network [18]. The bonding mechanisms of Farmville, such as sending gifts, working on cooperative crafting jobs, and trading goods in the farmer's market, allow these tightly knit groups to feel comfortable sharing their in-game benefits, playing experiences, and even generating mutual interests. The mechanism may also provide an alternative way for strong ties to interact in addition to the multiple communication channels such as face-to-face or other computer-mediated conversations. The aspects of ongoing in-game socialization and reciprocity found in bonding social capital may further provide emotional and substantive support for players. Thus, 
H5: There is a positive relationship between the intensity of Farmville play and players' perceived bonding social capital.

Research on social capital has been further extended to examine user's psychological wellness. Researchers have discovered positive effects of the Internet use on social ties and aspects of users' psychological well-being, such as self-esteem and life satisfaction [12]. Benkler [25] pointed out that social connectedness, psychological well-being, gratification, and material gain are found to motivate social mediause while others [26] have suggested that SNS users who actively engage in the site are more likely to perceive connectedness and feel happier. However, mixed results have also been produced when testing whether the association between SNS use and both dimensions of social capital varies depending on the level of the users' life satisfaction [12] [13].

Further, drawing parallels to the Internet addiction assumption, researchers hypothesized an association between game play and loneliness and found mixed results [27] [28]. In fact, the causal relationship between Internet use and loneliness is complicated. For example, researchers found people who are lonely, shy, or depressed are more likely to use the Internet to escape from daily life [29]. Lonely people are also more likely to use the Internet to search for new social contacts. Research on game play also found that gamers are motivated to play as a way of coping with loneliness [30]. Recent research demonstrated that loneliness was the cause and consequence of pathological game play [27]. Although the social capital resource of group attachment may relieve loneliness [20], the causality of game play and loneliness is unclear. In particular, the empirical support of causality of game play and psychological wellness is inconclusive. Thus,

H6a: The relationship between the intensity of Farmville play and bridging social capital varies depending on the level of the players' life satisfaction.

H6b: The relationship between the intensity of Farmville play and bonding social capital varies depending on the level of the players' life satisfaction.

H6c: The relationship between the intensity of Farmville play and bridging social capital varies depending on the level of the players' loneliness.

H6d: The relationship between the intensity of Farmville play and bonding social capital varies depending on the level of the players' loneliness.

\section{Method}

\subsection{Survey and Sample}

To capture a diverse and broad range of Farmville players in Taiwan, participants were recruited via popular game portal sites, Farmville fan groups on Facebook, and a popular bulletin board system (BBS). An online survey was fielded for 5 weeks. Participants who visited the survey link through any of the announcement channels were directed to a short description of the study, information about confidentiality, and incentives. As a reward, all participants were eligible to participate in a raffle of 100 gift certificates valued from the equivalent of US\$3 to US\$10.

After 11 duplicate responses were removed, 430 respondents (56.7\% male; $43.3 \%$ female), were retained for analysis. Respondents reported spending between 2 and $4 \mathrm{~h}$ online and 1 to $2 \mathrm{~h}$ on Facebook daily. They had an average of 303.11 Facebook friends $(S D=396.92)$. Farmville was developed in 2009; the respondents of this study reported to have had less than 6 months of playing history on average by the time they had completed the survey. The respondents, whose mean age was 27.5 (SD = 7.04), spent about 30 to $60 \mathrm{~min}$ on average playing the game daily. According to a large-scale survey of social game players in Taiwan, about $61.5 \%$ of the players were aged 21 to 30 years [31]. As the game was enjoyed by a wider age range of players, the standard deviation of respondents' age in this study was comparatively larger. The same study [31] also found that about $32.9 \%$ of the players reported playing social games for 21 to 60 min daily.

\subsection{Measures}

All scale items in this study were measured on a five-point Likert-type scale, ranging from 1 (strongly disagree) to 5 (strongly agree). Participants were asked to rate the extent to which they agreed or disagreed with each statement.

Connection Strategy. Eight items were developed to measure whether Farmville players were better able to connect with their acquaintances or to meet new people through the game. Using Farmville to connect with ex- 
isting ties was measured by a set of four questions such as "I started playing Farmville because my family and friends invited me" and "I would invite family and friends to play Farmville" (Cronbach's alpha $=0.81$ ). Whether Farm ville is used to link to new people was measured with a set of four questions, such as "I have in-game neighbors who are strangers I have never met in real life" and "I have accepted complete strangers' invitations as their in-game neighbors to play Farmville” (Cronbach’s alpha $=0.94$ ).

Farmville Intensity. To measure the extent to which Farmville players were engaged in the game, the Farmville intensity scale (Cronbach's alpha $=0.88$ ) was adapted from the Facebook intensity scale [12] with changes to the wording. Four additional items were created to facilitate the understanding of players' game-related behaviors in online and offline contexts, such as whether players would spend real money on in-game products, talk to other players about the game, or find information about the game online. The number of players' Farmville neighbors, play history, the highest level achieved, and the amount of time spent on the game on a typical day were also measured.

Satisfaction with Life. The Satisfaction with Life Scale [32] consisting of five-item instruments to measure global cognitive judgments of satisfaction with one's life were used in this study (Cronbach's $\alpha=0.91$ ).

Loneliness. The Revised UCLA (R-UCLA) scale [33] measures general feelings of social isolation and dissatisfaction with one's social relationships were adapted (Cronbach's $\alpha=0.83$ ).

Social Capital. To measure Farmville players' perceived social capital, twelve items from Williams' [21] Bridging (Cronbach's alpha $=0.95$ ) and Bonding Social Capital subscales (Cronbach's alpha $=0.89$ ) were adapted with changes made to reflect the context of Farmville play.

\section{Results}

To test whether the size of the Farmville players' network affected how they performed in the game, hierarchical regression analyses were conducted. As shown in Table 1, the block of demographic variables explained $49 \%$ of the variance; among them, gender (male, $\beta=0.103, \mathrm{p}<0.01$ ), age $(\beta=0.256, \mathrm{p}<0.001$ ), Facebook use per day $(\beta=0.149, \mathrm{p}<0.01)$, number of Facebook friends $(\beta=0.167, \mathrm{p}<0.001)$, and Farmville history $(\beta=0.467, \mathrm{p}<$ 0.001) were all significant predictors of Farmville game level. To explore the relationship between a player's game level and network size, demographic variables were entered in the first block followed by a second block that added number of Farmville neighbors. The number of Farmville neighbors alone was a significant predictor ( $\beta=0.263, \mathrm{p}<0.001$ ), accounting for $4.7 \%$ of the variance. Thus, $\mathrm{H} 1$ was strongly supported.

The same procedure was assessed to test whether two connection strategies were positively correlated to a player's game level. Adding these two variables raised the overall explained variance to $54.7 \%$. Once again, after controlling for demographic variables and number of Farmville neighbors, using only the game to link new people was statistically significant $(\beta=0.263, \mathrm{p}<0.001)$; thus, H3 was supported, but $\mathrm{H} 2$ was rejected (Table 1).

A series of regression analyses were conducted to examine the hypotheses regarding the relationship between Farmville play and two dimensions of social capital—bridging and bonding. In each regression model, demographic, connection strategy, and psychological wellness variables were controlled to determine whether Farmville play accounted for variance in social capital over and above these other independent variables (Table 2). H4 proposed a positive relationship between the intensity of Farmville play and a player's bridging social capital. As shown in Table 2, the demographic variables alone explained $12.3 \%$ of the variance. Internet use $(\beta=-0.260$, $\mathrm{p}<0.001)$, Facebook use per day $(\beta=0.339, \mathrm{p}<0.001)$, Farmville history $(\beta=0.151, \mathrm{p}<0.01)$, and age $(\beta=$ $0.115, \mathrm{p}<0.05$ ) were all significant predictors of bridging social capital. Two connection strategy variables and two psychological wellness variables were then added, increasing the variance explained to $65.7 \%$. Using the game to connect with existing ties $(\beta=0.583, \mathrm{p}<0.001)$, link to new people $(\beta=0.292, \mathrm{p}<0.001)$, and life satisfaction $(\beta=0.067, \mathrm{p}<0.05)$ were all significant predictors of bridging social capital. Farmville intensity was then entered after controlling for these variables and raised the statistic to $74.9 \%$. After controlling for demographic factors, connection strategies, and psychological wellness measures, the extent to which players engaged in Farmville play still contributed significantly to bridging social capital $(\beta=0.534, \mathrm{p}<0.001)$, supporting H4.

To test the relationship between Farmville intensity and bonding social capital, the same procedure was conducted. Demographic variables alone accounted for only $3.5 \%$ of the variance. Among them, only Internet use $(\beta=-0.147, \mathrm{p}<0.001)$ and Facebook use per day $(\beta=0.212, \mathrm{p}<0.001)$ were significant factors. As in the bridging model, general Internet use was negatively related to bonding social capital (Table 2). 
Table 1. Regressions predicting game level from number of Farmville friends and two connection strategies.

\begin{tabular}{|c|c|c|c|}
\hline & Model I & Model II & Model III \\
\hline & $\beta$ & $\beta$ & $\beta$ \\
\hline Intercept & -50.992 & -46.401 & -53.174 \\
\hline Gender: male & $0.103^{* *}$ & $0.101^{* *}$ & $0.103^{* *}$ \\
\hline Age & $0.256^{* * *}$ & $0.229^{* * *}$ & $0.224^{* * *}$ \\
\hline Internet use per day & 0.011 & 0.038 & 0.042 \\
\hline Facebook use per day & $0.149^{* *}$ & $0.106^{*}$ & 0.090 \\
\hline Number of Facebook friends & $0.167^{* * *}$ & 0.056 & 0.055 \\
\hline Members of extracurricular club & -0.093 & -0.080 & -0.073 \\
\hline Members of social group/org & 0.065 & 0.058 & 0.052 \\
\hline Farmville history (Until now, how long you've been playing Farmville?) & $0.467^{* * *}$ & $0.413^{* * *}$ & $0.385^{* * * *}$ \\
\hline Number of Farmville neighbors & & $0.263^{* * *}$ & $0.252^{* * *}$ \\
\hline Use Farmville to connect with existing ties & & & -0.042 \\
\hline Use Farmville to link new people & & & $0.128^{* *}$ \\
\hline \multirow[t]{2}{*}{$\mathrm{N}=430 \mathrm{R}^{2}$} & $\mathrm{~F}=52.596^{* * *}$ & $\mathrm{~F}=56.270^{* * *}$ & $\mathrm{~F}=48.109^{* * *}$ \\
\hline & 0.490 & 0.537 & 0.547 \\
\hline$\left(\Delta \mathrm{R}^{2}\right)$ & & 0.047 & 0.010 \\
\hline
\end{tabular}

Notes: ${ }^{1}$ Nominal factors expanded to all levels; ${ }^{2}$ Continuous factors centered by mean, scaled by range $/ 2 ;{ }^{3 *} \mathrm{p}<0.05,{ }^{* *} \mathrm{p}<0.01,{ }^{* * *} \mathrm{p}<0.001$.

Table 2. Regressions predicting bridging and bonding social capital from Farmville intensity and psychological wellness.

\begin{tabular}{|c|c|c|c|c|c|c|c|c|}
\hline \multirow{3}{*}{ Independent variables ${ }^{1}$} & Model I & Model II & Model III & Model IV & Model I & Model II & Model III & Model IV \\
\hline & \multicolumn{3}{|c|}{ Bridging social capital } & & & \multicolumn{3}{|c|}{ Bonding social capital } \\
\hline & $\beta$ & $\beta$ & $\beta$ & $\beta$ & $\beta$ & $\beta$ & $\beta$ & $\beta$ \\
\hline Intercept & 2.813 & 0.362 & 0.579 & 1.181 & 2.951 & 0.620 & 0.749 & 1.882 \\
\hline Gender: male & 0.069 & -0.012 & -0.011 & -0.015 & -0.007 & $-0.094^{*}$ & $-0.094^{*}$ & $-0.089^{*}$ \\
\hline Age & $0.115^{*}$ & 0.005 & $-0.055^{*}$ & -0.053 & 0.048 & -0.020 & -0.053 & 0.050 \\
\hline Internet use/day & $-0.260^{* * *}$ & -0.103 & $-0.099^{* *}$ & $-0.096^{* *}$ & $-0.147^{*}$ & -0.024 & -0.022 & -0.021 \\
\hline Facebook use/day & $0.339^{* * *}$ & $0.118^{* *}$ & 0.020 & 0.017 & $0.212^{* *}$ & 0.075 & 0.022 & 0.020 \\
\hline Number of Facebook friends & 0.051 & 0.017 & -0.023 & -0.022 & 0.035 & 0.020 & -0.001 & 0.002 \\
\hline $\begin{array}{c}\text { Members of } \\
\text { extracurricular club }\end{array}$ & $-0.104^{*}$ & 0.013 & 0.036 & 0.033 & -0.104 & -0.005 & 0.007 & 0.006 \\
\hline Members of social group/org & -0.046 & -0.022 & -0.021 & -0.025 & -0.085 & -0.025 & -0.024 & -0.022 \\
\hline Farmville history & $0.151^{* *}$ & 0.012 & $0.110^{* * * *}$ & $0.114^{* * *}$ & -0.040 & -0.080 & $-0.146^{* *}$ & $-0.147^{* *}$ \\
\hline $\begin{array}{l}\text { Use FV to connect with } \\
\text { existing ties }\end{array}$ & & $0.583^{* * *}$ & $0.317^{* * *}$ & $0.312^{* * *}$ & & $0.540^{* * * *}$ & $0.394^{* * *}$ & $0.396^{* * *}$ \\
\hline Use FV to link new people & & $0.292^{* * *}$ & $0.195^{* * *}$ & $0.196^{* * *}$ & & -0.074 & $-0.127^{* *}$ & $-0.126^{* *}$ \\
\hline Life satisfaction & & $0.067^{*}$ & 0.026 & 0.017 & & $0.231^{* * *}$ & $0.208^{* * * *}$ & -0.009 \\
\hline Loneliness & & -0.032 & -0.029 & $-0.181^{*}$ & & -0.044 & -0.043 & -0.134 \\
\hline Farmville intensity & & $0.534^{* * *}$ & & $0.344^{*}$ & & & $0.292^{* * * *}$ & -0.051 \\
\hline $\begin{array}{l}\text { FV intensity by life } \\
\text { satisfaction }\end{array}$ & & & & 0.023 & & & 0.366 & \\
\hline $\begin{array}{l}\text { FV intensity by } \\
\text { loneliness }\end{array}$ & & & & 0.212 & & & 0.132 & \\
\hline $\mathrm{N}=430 \mathrm{~F}$ & $8.519^{* * *}$ & $69.358^{* * *}$ & $99.230^{* * *}$ & $86.612^{* * * *}$ & $2.950^{* * *}$ & $27.434^{* * *}$ & $28.159^{* * *}$ & $24.664^{* * *}$ \\
\hline $\mathrm{R}^{2}$ & 0.123 & 0.657 & 0.749 & 0.750 & 0.035 & 0.425 & 0.451 & 0.453 \\
\hline$\left(\Delta \mathrm{R}^{2}\right)$ & & 0.534 & 0.090 & 0.002 & & 0.390 & 0.027 & 0.004 \\
\hline
\end{tabular}

Notes: ${ }^{1}$ Nominal factors expanded to all levels; ${ }^{2}$ Continuous factors centered by mean, scaled by range $2 ;{ }^{3 *} \mathrm{p}<0.05,{ }^{* *} \mathrm{p}<0.01,{ }^{* * *} \mathrm{p}<0.001 ;{ }^{4}$ Only one interaction term was entered at a time in each regression. 
After controlling for demographic variables, two connection strategy variables and two psychological variables were entered, raising the explained variance to $42.5 \%$. In this model, life satisfaction was significantly correlated to bonding social capital $(\beta=0.231, \mathrm{p}<0.001)$, suggesting that players who had higher levels of life satisfaction may perceive more bonding social capital.

Using the game to connect to existing ties was positively correlated to bonding social capital $(\beta=0.642, \mathrm{p}<$ $0.001)$ while a negative correlation was found in using the game to link to new people $(\beta=-0.093, \mathrm{p}<0.05)$. These findings demonstrate that players who tend to use the game to connect with acquaintances may gain more in bonding social capital whereas players who used the game to link to new people may perceive less.

Finally, after controlling for demographic variables, connection strategy variables, and psychological wellness variables, Farmville intensity was still a significant predictor of bonding social capital $(\beta=0.292, \mathrm{p}<0.001)$, and H5 was supported. Gender (female, $\beta=0.094, \mathrm{p}<0.05)$ and Farmville history $(\beta=-0.146, \mathrm{p}<0.01$ ) were also significant, suggesting women and players with shorter playing history may perceive more bonding social capital. Overall, the independent factors accounted for $45.1 \%$ of the variance.

H6a, 6b, 6c, and 6d predicted the relationship between Farmville play and both dimensions of social capital would vary depending on the level of a player's psychological wellness. As shown in Table 2, loneliness was negatively correlated to bridging social capital $(\beta=-0.181, \mathrm{p}<0.05)$, indicating that players who were lonelier may perceive more bridging social capital. However, none of the interactions were significant, and H6a, 6b, 6c, and 6 dwere all rejected.

\section{Discussion}

Using survey data collected from Farmville players in Taiwan, the current study showed a positive relationship between the intensity of Farmville play and both dimensions of social capital. The study extended the popular assumption that using SNSs contributes to the perception of social capital to social game play and accumulation of social capital more specifically. The Facebook intensity scale [12] was successfully adapted and further developed to measure Farmville play.

Moreover, whether the relationship between Farmville play and social capital variables was moderated by levels of players' psychological wellness was explored. Interestingly, players who were more satisfied with life perceived higher sense of bridging and bonding social capital but they may not gain even more with intensive play. Although lonelier players tended to perceive more bridging social capital, intensive game play may not be helpful to tackle real-life problems either. One explanation is that given the casual setting of social gaming, the effect of playing in coping with real-life difficulties may not be particularly salient. For people with an inherently higher sense of psychological wellness, casual play may not reinforce their sense of social capital either.

The empirical findings of this study suggested a number of important implications for understanding how individuals mobilize their social networks and foster a sense of belonging and psychological wellness in the context of social gaming. First, previous research developed various measures for examining negative consequences of online game play, such as addiction, aggression, and withdrawal symptoms [34]. Other researchers found that social interaction is a factor for playing online videogames in the massive player game setting [2]. Game play provides emotional and social support for players to relieve stress, loneliness, and boredom [35]. This study found that Farmville players were more likely to perceive higher sense of social capital if they played the game more intensively and psychological wellness may also serve as predictors of social capital. However, the extent to which intensive Farmville play may lead to the psychological benefits of enhanced life satisfaction and reduced loneliness is unclear. Researchers have found mixed results in terms of whether Facebook use can help users who had low life satisfaction to overcome social barriers [12] [13]. The causal relationship between social game play and socio-psychological perception is nuanced and needs more attention. The "rich get richer" or "poor get richer" Internet paradox may still be of interest to future studies by adding more contextual variables.

However, in addition to the positive relationship between Farmville play and social capital, another interesting finding was that general Internet use was negatively correlated to bridging and bonding social capital whereas Facebook use was positively correlated. That is, spending more time on general Internet use may not provide a higher perception of social capital. Rather, the hours spent on Facebook, and the engagement of Farmville play, in particular, may contribute more to both dimensions of social capital. Thus, it may be less about how long people spend on the Internet for general use, and more about what they do online in perceiving the sense of social capital. 
Second, previous research suggested that easy entrance into the community results in less bonding social capital. Online communities were influenced by easy entry and exit and thus tended to promote weaker tie based bridging social capital instead of bonding [21]. Although the social gaming community is easy to join and is free, this study found people who played Farmville more were more likely to perceive higher bonding social capital. Moreover, in the context of online games, the characteristics of online social networks were broad and thus can function better as bridging mechanisms than as bonding ones [7]. In this study, players who tended to add formerly unknown others mainly for gaming purposes were more likely to perform better in the game. Here, having more people to play the game with was more helpful to progress in the game but using the game to connect with existing contacts was not positively related to a player's overall game level. In this sense, other socio-psychological benefits may be provided by acquaintances that cannot be measured solely based on achievements in the game.

More precisely, although linking new people through the game may provide resources to help players advance, bonding social capital was perceived if players tended to connect with existing contacts through gaming. Findings here provide empirical support to the strength of weak tie and benefits of strong tie networks. It illustrates that players' connection strategies do matter by elaborating how players may gain instrumental support in advancing in the game through weak ties and perceive emotional support via their strong tie networks. It can also be understood that the design of social games is centered on sociability and playfulness while the mechanism of gaming requires collaboration and mutual aid. Success in social games may rely on how players leverage their weak tie networks. However, conversation and socialization among acquaintance are more likely to encourage emotional or substantive support.

Another interesting finding was that Farmville players perceived more bridging social capital if they played the game longer. Players who had shorter gaming history, rather than long-term players, perceived a higher sense of bonding social capital. These findings reveal that game intensity may not be necessarily equivalent to how long they have been playing the game. Game intensity may be less about frequency or duration and more about the extent to which players are attached and engaged. Further, players may initially start playing with their close ties and feel bonded. But, it takes longer to link to more people to progress in the game, and thus bridging social capital may be perceived over time. Given the social setting, low barrier, and low cost of the social game characteristics, newcomers are easily attracted as a way to interact with acquaintances. However, they may not foster long-term engagement and are easily distracted by other new games that are continually developed and free to enter. What makes social game players disengaged may also be interesting to explore.

Finally, the structure and characteristics of MMORPGs were heavily embedded in synchronous collaboration and communication [7]. For example, conversation, text and voice based, played an essential role within a one-to-one or one-to-many communicative virtual space for players to meet diverse challenges as well as to create and maintain relationships with other players [7]. In the social game setting, however, players are more likely to play the game asynchronously without real time play interaction. The asynchronous multiplayer concept emphasizes playing in sequence rather than in tandem and real time; actual interaction among different players is not a prerequisite [11]. The findings suggest that the nuances of sociability, synchronously or asynchronously, in the online gaming community may contribute to forming bridging social capital and may likely foster the sense of bonding social capital.

The limitations of this study are that it examined only one particular social game, Farmville, and thus, the findings may not be generalized to all kinds of social games. In addition, this study used a purposive sample drawn from Farmville players in Taiwan, and did not compare the perception of social capital between players and non-players. Future research may consider a probability sample. The results are not necessarily causal due to cross-sectional design of the study. The results may not generalize to the online gaming context, either. A study of long term change in a different cultural context may offer insightful explanations. Future research may collect longitudinal data through different kinds of social game players.

\section{Acknowledgements}

This study is supported by the National Science Council, Taiwan.

\section{References}

[1] Rheingold, H. (2000) The Virtual Community: Homesteading on the Electronic Frontier. The MIT Press, Boston. 
[2] Griffiths, M.D., Davies, M.N.O. and Chappell, D. (2003) Breaking the Stereotype: The Case of Online Gaming. Cyber Psychology \& Behavior, 6, 81-91. http://dx.doi.org/10.1089/109493103321167992

[3] Yee, N. (2006) Motivations for Play in Online Games. Cyber Psychology \& Behavior, 9, 772-775. http://dx.doi.org/10.1089/cpb.2006.9.772

[4] Ducheneaut, N., Moore, R. J. and Nickell, E. (2007) Virtual “Third Places”: A Case Study of Sociability in Massively Multiplayer Games. Computer Supported Cooperative Work, 16, 129-166. http://dx.doi.org/10.1007/s10606-007-9041-8

[5] Nardi, B. and Harris, J. (2006) Strangers and Friends: Collaborative Play in World of Warcraft. In: Proceedings of CSCW 2006, ACM Press, New York, 149-158.

[6] Williams, D., Kennedy, T.L.M. and Moore, R.J. (2011) Behind the Avatar: The Patterns, Practices, and Functions of Role Playing in MMOs. Games and Culture, 6, 171. http://dx.doi.org/10.1177/1555412010364983

[7] Steinkuehler, C.A. and Williams, D. (2006) Where Everybody Knows Your (Screen) Name: Online Games as "Thirdplaces”. Journal of Computer Mediated Communication, 11, 885-909. http://dx.doi.org/10.1111/j.1083-6101.2006.00300.x

[8] Peña, J. and Hancock, J.T. (2006) An Analysis of Socioemotional and Task Communication in Online Multiplayer Video Games. Communication Research, 33, 92. http://dx.doi.org/10.1177/0093650205283103

[9] Lee, Y.H. and Wohn, D.Y. (2012) Are There Cultural Differences in How We Play? Examining Cultural Effects Onplaying Social Network Games. Computers in Human Behavior, 28, 1307-1314. http://dx.doi.org/10.1016/j.chb.2012.02.014

[10] Hou, J. (2011) Uses and Gratification of Social Games: Blending Social Networking and Gameplay. First Monday, 16. http://dx.doi.org/10.5210/fm.v16i7.3517

[11] Di Loreto, I. and Gouaich, A. (2010) Social Casual Games Success Is Not So Casual. Proceeding of the 28th ACM Conference on Human Factors in Computing Systems, Atlanta, 10-15 April 2010, 001-011.

[12] Ellison, N.B., Steinfield, C. and Lampe, C. (2007) The Benefits of Facebook “Friends": Social Capital and College Students’ Use of Online Social Network Sites. Journal of Computer-Mediated Communication, 12, 1143-1168. http://dx.doi.org/10.1111/j.1083-6101.2007.00367.x

[13] Valenzuela, S., Park, N. and Kee, K.F. (2009) Is There Social Capital in a Social Network Site? Facebook Use and College Students' Life Satisfaction, Trust and Participation. Journal of Computer-Mediated Communication, 14, 875901. http://dx.doi.org/10.1111/j.1083-6101.2009.01474.x

[14] Skoric, M.M. and Kwan, G.C.E. (2011) Platforms for Mediated Sociability and Online Social Capital: The Role of Facebook and Massively Multiplayer Online Games. Asian Journal of Communication, 21, 467-484. http://dx.doi.org/10.1080/01292986.2011.587014

[15] Coleman, J.S. (1988) Social Capital in the Creation of Human Capital. American Journal of Sociology, 94, 95-120. http://dx.doi.org/10.1086/228943

[16] Adler, P.S. and Kwon, S.W. (2002) Social Capital: Prospects for a New Concept. Academy of Management Review, 27, $17-40$.

[17] Lin, N. (1999) Building a Network Theory of Social Capital. Connections, 22, 28-51.

[18] Wohn, D.Y. (2012) The Role of Habit Strength in Social Network Game Play. Communication Research Reports, 29, 74-79. http://dx.doi.org/10.1080/08824096.2011.639912

[19] Vergeer, M. and Pelzer, B. (2009) Consequences of Media and Internet Use for Offline and Online Network Capital and Well-Being. A Causal Model Approach. Journal of Computer-Mediated Communication, 15, 189-210. http://dx.doi.org/10.1111/j.1083-6101.2009.01499.x

[20] Putnam, R.D. (2001) Bowling Alone: The Collapse and Revival of American Community. Simon and Schuster, New York.

[21] Williams, D. (2006) On and off the Net: Scales for Social Capital in an Online Era. Journal of Computer Mediated Communication, 11, 593-628. http://dx.doi.org/10.1111/j.1083-6101.2006.00029.x

[22] Vitak, J., Ellison, N.B. and Steinfield, C. (2011) The Ties That Bond: Re-Examining the Relationship between Facebook Use and Bonding Social Capital. Proceedings of the 44th Hawaii International Conference on System Sciences, Koloa, 4-7 January 2011, 1-10.

[23] Burke, M., Marlow, C. and Lento, T. (2010) Social Network Activity and Social Well-Being. Proceeding of the 28th ACM Conference on Human Factors in Computing Systems, Atlanta, 10-15 April 2010, 1909-1912.

[24] Smyth, J.M. (2007) Beyond Self-Selection in Video Game Play: An Experimental Examination of the Consequences of Massively Multiplayer Online Role-Playing Game Play. Cyber Psychology \& Behavior, 10, 717-721. 
http://dx.doi.org/10.1089/cpb.2007.9963

[25] Benkler, Y. (2006) The Wealth of Networks: How Social Production Transforms Markets and Freedom. Yale University Press, New Haven.

[26] Valkenburg, P.M., Peter, J. and Schouten, A.P. (2006) Friend Networking Sites and Their Relationship to Adolescents' Well-Being and Social Self-Esteem. Cyber Psychology \& Behavior, 9, 584-590. http://dx.doi.org/10.1089/cpb.2006.9.584

[27] Lemmens, J.S., Valkenburg, P.M. and Peter, J. (2009) Development and Validation of a Game Addiction Scale for Adolescents. Media Psychology, 12, 77-95. http://dx.doi.org/10.1080/15213260802669458

[28] Kim, H.K. and Davis, K.E. (2009) Toward a Comprehensive Theory of Problematic Internet Use: Evaluating the Role of Self-Esteem, Anxiety, Flow and the Self-Rated Importance of Internet Activities. Computers in Human Behavior, 25, 490-500. http://dx.doi.org/10.1016/j.chb.2008.11.001

[29] Vorderer, P., Klimmt, C. and Ritterfeld, U. (2004) Enjoyment: At the Heart of Media Entertainment. Communication Theory, 14, 388-408.

[30] Klimmt, C. and Hartmann, T. (2008) Mediated Interpersonal Communication in Multiplayer Video Games: Implications for Entertainment and Relationship Management. In: Konijn, E.A., Utz, S., Tanis, M. and Barnes, S.B., Eds., Mediated Interpersonal Communication, Routledge, New York, 309-330.

[31] Market Intelligence and Consulting Institute (2010) Game Market. MIC, Taipei. (in Chinese)

[32] Diener, E.D., Emmons, R.A., Larsen, R.J. and Griffin, S. (1985) The Satisfaction with Life Scale. Journal of Personality Assessment, 49, 71-75. http://dx.doi.org/10.1207/s15327752jpa4901_13

[33] Russell, D.W. (1996) UCLA Loneliness Scale (Version 3): Reliability, Validity and Factor Structure. Journal of Personality Assessment, 66, 20-40. http://dx.doi.org/10.1207/s15327752jpa6601_2

[34] Mehroof, M. and Griffiths, M.D. (2010) Online Gaming Addiction: The Role of Sensation Seeking, Self-Control, Neuroticism, Aggression, State Anxiety and Trait Anxiety. Cyber Psychology, Behavior and Social Networking, 13, 313-316. http://dx.doi.org/10.1089/cyber.2009.0229

[35] Wack, E. and Tantleff-Dunn, S. (2009) Relationships between Electronic Game Play, Obesity and Psychosocial Functioning in Young Men. Cyber Psychology \& Behavior, 12, 241-244. http://dx.doi.org/10.1089/cpb.2008.0151 
Scientific Research Publishing (SCIRP) is one of the largest Open Access journal publishers. It is currently publishing more than 200 open access, online, peer-reviewed journals covering a wide range of academic disciplines. SCIRP serves the worldwide academic communities and contributes to the progress and application of science with its publication.

Other selected journals from SCIRP are listed as below. Submit your manuscript to us via either submit@scirp.org or Online Submission Portal.
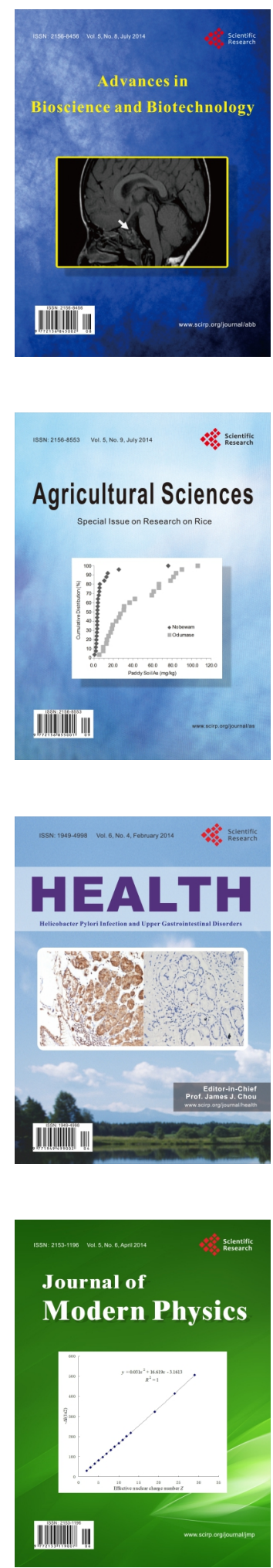
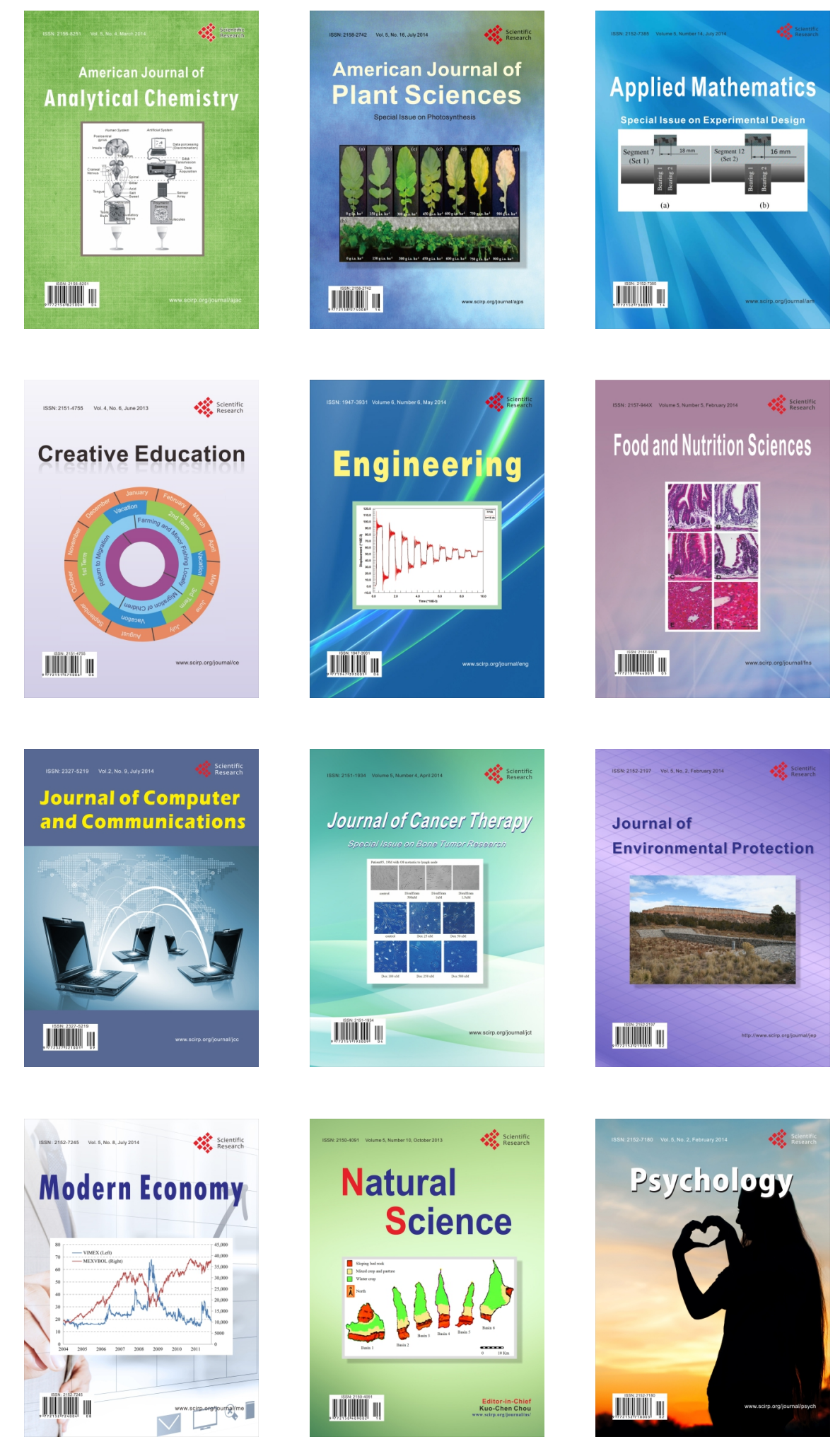